\title{
Rice husk ash as a potential carrier for the immobilisation of lipases to applied in the enzymatic production of biodiesel
}

\author{
Kírian Bonet-Ragel, Lucia López-Pou, Glsela Tutusaus, M. Dolors Benaiges, Francisco Valero* \\ Department of Chemical, Biological and Environmental Engineering, School of Engineering, \\ Universitat Autònoma de Barcelona, 08193 Bellaterra, Barcelona (Spain)
}

${ }^{*}$ Corresponding author

Dr. Francisco Valero

Department of Chemical, Biological and Environmental Engineering, School of Engineering Universitat Autònoma de Barcelona

Phone +34 (93) 5811809

Fax +34 (93) 5812013

e-mail address: francisco.valero@uab.cat

Keywords: Rhizopus oryzae lipase, biodiesel, rice husk ash, immobilisation

\begin{abstract}
The potential application of rice husk ash (RH26) as support for the immobilisation of a recombinant Rhizopus oryzae ( $\mathrm{rROL}$ ) lipase as biocatalyst in the enzymatic biodiesel production using alperujo oil and the comparison with commercial hydrophobic support OD403 (RelOD) has been made. Although the specific activity (UA mg support ${ }^{-1}$ ) was around a half lower in $\mathrm{RH} 26$ than in RelOD when they were used as biocatalyst in biodiesel reaction the normalised
\end{abstract}


initial rate was similar, between 1.6 -2.4 $\mu \mathrm{mol}$ FAME $\mathrm{ml}^{-1} \mathrm{ml}^{-1} \mathrm{UA}^{-1}$. Thus in terms of biocatalysis performance rice husk as is an alternative to commercial supports. However the main problem is the more complex recovery of $\mathrm{RH} 26$ for the reutilization compared with commercial ones.

\section{Introduction}

Rice husk ash (RHA) from rice husk (RH) biomass power plant is abundantly available in rice producing countries as a waste, recycling mainly for low-value applications. For instance, in Asia countries it is used in RH gasification power generation, obtaining RHA as a waste product under a control of the temperature in the burning process (Pode 2016). RHA is mainly composed by $\mathrm{SiO}_{2}$ - about $95 \%$ - and other trace elements like potassium, calcium, magnesium, iron, copper, manganese and zinc (Della 2002). This composition of RHA makes it a candidate in industrial applications, with the advantage of its low cost (Turmanova 2012).

Three different types of RHA from the incarceration of $\mathrm{RH}$ depending of the temperature can be obtained: amorphous, partially crystalline and crystalline, the first one is considered the most active (Vinh 2012), with pore distribuition as mesoporous (Srivastava 2005).

There is a big number development of RHA uses with high potential future applications due to its hydrophibicity (Pode 2016; Andreola 2013).

Concretely, applications in the basic catalysis of biodiesel production to its use as natural adsorbent for improving the quality of waste frying oil by removing its free fatty acids are related (Ismail 2015). Also by monoglyceride removal in crude biodiesel production by coating aluminium oxide on extracted silica from RHA (Saengprachum 2016), as support of vanadium pentoxide to use in the transesterification of different tryglucerides sources using as acyl-acceptor group ethanol (Almeida 2016).

Recently RHA has been used as a carrier, using cross-linking and adsorption methods, for the recovery of activity Candida antarctica lipase B (CALB) with good results, but also increasing stability, reusability and application adaptability of the biocatalyst (Ulker 2016ª) and applied in the biosynthesis of poly ( $\varepsilon$-caprolactone) (Ulker $2016^{\mathrm{b}}$ ).

Although the biodiesel production through basic chemical transesterification is mainly used, enzymatic transesterification using lipases has become a real alternative to chemical process in the last years. This is due to its advantage as a green bioprocess using less energy, biodiesel recovery is minimized since no emulsions are presented, with the implementation of less units operations (Rodrigues 2016) and with the attractive to work directly with substrates 
containing high quantity of free fatty acids (Gogh 2012, Fan 2012, Juan 2011, Rodrigues 2016). However, its industrial implementation is limited by a longer reaction time, the well-known lipase denaturation and inhibition by methanol (ethanol), the cost of the biocatalyst (You 2013 Canet 2014; Duarte 2015; Kuo 2015, Lotti 2015) and the problems associated to the presence of glycerol. This by-product adsorbs onto carriers when lipase is immobilized provoking lipase deactivation and diminishing the efficiency of the process (Hama 2011).

To avoid part of these problems some recombinant 1-3 positional specific lipases has been used, avoiding the presence of glycerol as by product, obtaining as final product 2monoglycerides (Calero 2014) and minimized the cost of the enzyme due to the production in cell factories (Arnau 2010).

On the other hand, lipases are majority applied in biodiesel synthesis immobilized on commercial supports. Thus, the use of cheaper supports is a clear strategy to diminish the cost of this bioprocess.

Recently RHA has been used as support for the immobilisation of recombinant Rhizopus oryzae lipase ( $\mathrm{rROL}$ ) demonstrating the viability of this support as alternative to commercial lipases (Martin 2013). The performance of rROL immobilized on commercial supports under different strategies in biodiesel production has been deeply studied (Canet et al. 2014, Canet 2016, Bonet-Ragel 2016, Canet 2017).

The objective of this study is the comparison of the performance of rROL immobilized by adsorption on commercial hydrophobic support OD403 (RelOD) and rice husk ash (RH26) in the enzymatic biodiesel production using alperujo oil, a waste oil rich in free fatty acids (FFA) using methanol as acyl-acceptor in terms of immobilisation performance, initial FAMES production reaction rate.

\section{Materials and methods}

\subsection{Materials}

Recombinant Rhizopus oryzae lipase was produced by the Bioprocess Engineering and Applied Biocatalysis group from Universitat Autónoma de Barcelona (UAB) following production methods referenced in previous works (Arnau et al., 2010). Olive waste oil (alperujo) was kindly donated from Sierra Mágina olive oil extraction mill (Jaén, Spain).

Heptane, methanol and acetone were purchased from Panreac (Barcelona, Spain). Buffer constituents tris-(hydroxymethyl)-aminomethane, di-sodium hydrogen phosphate anhydrous and hydrochloric acid (37\% purity) were obtained from Scharlab (Barcelona, Spain). Oleic acid 
and calibration standards of methyl palmitate, methyl stearate, methyl oleate, methyl linoleate and methyl linolenate were obtained from Sigma-Aldrich (St Louis, US). Colorimetric kit for enzymatic assay (11821729) was acquired from Roche (Mannheim, Deuschland). RH26 support was kindly donated by Dr. Maria de los Ángeles Martín Luengo from ICMM-CSIC (Madrid). Relizyme OD403 carrier was purchased from Resindion (Milano, Italy).

\subsection{Enzyme recovery, lyophilisation and storage}

Once performed Pichia pastoris fermentation, the recombinant enzyme obtained should be recovered and purified. Since Rhizopus oryzae is mostly extracellular, the medium is firstly centrifuged at $10000 \mathrm{rpm}$ during 10 minutes. Supernatant is then vacuum filtered in order to remove remaining cells and other solids in suspension. Ultrafiltration is needed afterwards, concentrating 10 times the initial volume. This is achieved with the equipment Centrasette ${ }^{\circledR}$ Pall Filtron (New York, US), using a 10kDa-cut off membrane.

The remaining fluid contains a high amount of salts. In order to reduce this concentration, it is diluted to meet the initial volume using Tris buffer $10 \mathrm{mM}$, and after diafiltered by membrane until the volume is reduced again 10 times. The resulting quantity is then frozen at $-20 \circ \mathrm{C}$. Lyophilization is finally performed at $-50 \circ \mathrm{C}$ and 100 torr during $48-72$ hours, after which the resulting enzyme is recovered and stored at -20 ㅇ C (Guillén 2012)

\subsection{Lipolytic activity}

Lipolytic activity of enzyme solutions is obtained following the modified method described by Roche, enabling to use their colorimetric kit assay. The procedure is always performed in triplicates, where $500 \mu \mathrm{L}$ of sample are mixed with $500 \mu \mathrm{L}$ of Tris- $\mathrm{HCl}$ buffer $(\mathrm{pH} 7.25)$ and 300 $\mu \mathrm{L}$ of Roche reagent in $1.5 \mathrm{~mL}$ cuvettes.

They are then introduced in the Cary Varian 300 spectrophotometer (Palo Alto, US) at 30ㄷ and $580 \mathrm{~nm}$ measuring their absorbance for 7 minutes. (Resina 2004).

\subsection{Lipase immobilisation}

In order to immobilize rROL in support RelOD/RH26, $5 \mathrm{mM}$ phosphate buffer at $\mathrm{pH} 7.5$ is prepared. The appropriate amount of buffer is mixed with lyophilized lipase in order to get solutions ranging its activity between $90-1800 \mathrm{UA} / \mathrm{mL}$. The resulted mixture is kept under magnetic stirrer for 30 minutes at $4 \stackrel{\circ}{ } \mathrm{C}$ until rROL is totally dissolved. 
On the other hand, support must be treated before immobilisation. The total weight must be put in contact with $100 \mathrm{~mL}$ of water-acetone solution (50/50 v/v) and let it under low stirring for 30 minutes at room temperature. After that, solution and support are separated by vacuum filtration, washing with distilled water for complete acetone removal.

Pretreated RelOD/RH26 is mixed with phosphate-lipase solution and kept under low stirring for 7 hours either at $4^{\circ} \mathrm{C}$ or $25^{\circ} \mathrm{C}$, depending on the experiment. When finished, the enzyme immobilized is separated from solution by vacuum filtration washing with phosphate buffer, and let it dry with silica gel, at room temperature, in a desiccator until its weight reached a constant value (1-2 days). Enzyme lyophilized is stored at $-20^{\circ} \mathrm{C}$.

\subsection{Transesterification reactions}

Transesterification reactions are carried out in $10 \mathrm{~mL}$ closed vials placed in an incubator (IKA KS 400 , Staufen, Deutschland) at 30ㄷ under continuous orbital stirring (350 rpm). Solvent and water-free reactions are performed stepwise adding each time $0.16 \mathrm{~mL}$ of methanol to the $8 \mathrm{~g}$ of alperujo substrate (previously dewaxed by centrifugation) and $150 \mathrm{mg}$ of selected biocatalyst.

Biocatalyst is easily recovered after each reaction. Its deposition allows removing the reaction medium, washing it with heptane - acetone - heptane and keep the biocatalyst stored afterwards at 4 으 $\mathrm{Cuntil}$ it is reused in order to perform cycles.

\subsection{FAME and oleic acid analysis}

Fatty acid methyl esters and total oleic acid amount were analysed by gas chromatography (GC) following the referenced work (Canet 2014). 


\section{Results and discussion}

\subsection{Immobilisation of rROL on RH26 and RelOD. Comparison.}

Two immobilisation processes were performed. In one hand, rROL was adsorbed on RelOD after its acetone pretreatment during 7 hours (Canet 2014). This is consistent with the fact that multipoint interaction between the non-complementary enzyme and the surface is a low and time-dependent process that requires correct alignment of groups (Mateo 2007). By the other hand, rROL was also immobilised by hydrophobic adsorbtion on rice husk ash support RH26 using the same method (Canet 2014), which has an amorphous surface due to its silica composition (Martin 2014).

A range of lipase solutions from 50 to $1800 \mathrm{UA} / \mathrm{mL}$ was performed in order to evaluate the optimal lipase load in the immobilisation process for each support.

Whereas enzyme performance was known to be better at lower temperature, moderately higher ones may favour the vibration of enzyme and support, increasing the possibilities of getting more enzyme-support linkages (Mateo 2007). However, temperature should not be too high since this may cause enzyme denaturation. Thus, for commercial support two temperatures were tested.

In order to ensure if temperature had a significant effect on the lipase stability during the immobilisation, two rROL solutions with similar initial activity were prepared. They were left at room temperature $\left(25^{\circ} \mathrm{C}\right.$ ) and $4^{\circ} \mathrm{C}$. Lipolytic activity (expressed in $\mathrm{UA} / \mathrm{mL}$ ) was followed during the next 4 hours that corresponds to the immobilisation time described in Materials and Methods. As shown in Table 1, activity remained the same along the time regardless of the temperature.

As shown in Fig. 1, it can be noted that increasing the initial lipolytic activity lead to an equal increasing in the lipase immobilised on the support and to a proportional decrease of immobilisation yield. However, specific lipolytic activity remains almost constant (saturation) when higher values than $800 \mathrm{UA} / \mathrm{mL}$ were offered.

As it was expected, immobilisation higher loads of lipase activity at room temperature showed more adsorption capacity than at $4^{\circ} \mathrm{C}$, without enzyme denaturation. 
In the case of alternative support RH26, shown in Fig 2., the immobilisation capacity at room temperature showed the same profile as the commercial one. Nevertheless, it seemed that immobilisation capacity decreased when higher loads than $800 \mathrm{UA} / \mathrm{mL}$ were offered $(1000$ $\mathrm{UA} / \mathrm{mL}$ ). However, support was able to adsorb more enzyme as loading values increased up to $1800 \mathrm{UA} / \mathrm{mL}$, leading to believe in a possible double-layer effect since lipases linked in the carrier surface were able to act as an adsorption sites for other lipases, conforming a second layer of enzyme (Masel 1996).

\subsection{Biodiesel initial rates.}

In order to test if the obtained biocatalysts showed mass transfer problems, enzymatic biodiesel reactions were performed. As shown in Materials and Methods, alperujo oil was used as a substrate. This waste oil showed a high efficiency in biodiesel synthesis due to its free fatty acid content giving a high stability to the biocatalyst and enhancing the initial rate (BonetRagel 2015).

Since complete reactions were no needed for these cases, only a pulse of $160 \mu \mathrm{L}$ of methanol was added to the reaction in order to avoid lipase inactivation and initial rate for each reaction was calculated, corresponding to the maximum conversion of $14 \%$. Fig 3 shows the values obtained for each biodiesel reaction, using both biocatalysts (RelOD and RH26). It can be noted that there is a linear correlation between initial rate and specific activity when lower values of it were used for both types of biocatalysts. In the case of ReIOD, it is observed that initial rate remained the same for specific activities up to $46 \mathrm{UA} / \mathrm{mg}$. This led to the conclusion that it was not worth working at values higher than $60-80 \mathrm{UA} / \mathrm{mg}$ at these specified transesterification condition.

Table 2 shows a summary of the most significant results obtained and compared with previous works in the same group. For better comprehension and comparison, initial rate values were divided by total lipolytic activity present in the reaction (biocatalyst weight $\mathrm{x}$ specific activity) obtaining a normalised value for each case. It is clear that maximum initial rates were achieved (2.37 $\mu \mathrm{mol} \mathrm{FAME} / \mathrm{mL} \cdot \mathrm{min} \cdot \mathrm{UA})$ at some particular values of specific activity, for the commercial $\operatorname{RelOD}(46.21 \mathrm{UA} / \mathrm{mg})$.

\subsection{Biodiesel production}


Based on previous conclusions, a complete transesterification reaction was performed using the commercial RelOD support. Biodiesel production was carried out with 5 pulses of methanol - each pulse was added every 45 minutes- aiming to achieve the maximum yield of $66 \%$ and to avoid enzyme deactivation (Lotti 2015). This is due to the use of a 1,3-positional specific lipase (see Materials and Method), which leaves $2^{\text {nd }}$ position of triacylglycerol unreacted. Acyl migration was not considered here, since much longer time would be needed (Kaieda 1999) and no glycerol as a product was detected in medium.

Figure 4 shows complete reaction after 225 minutes, achieving a $64.5 \%$ of FAME yield (nearly a $98 \%$ of real yield). Through a periodical methanol addition, FAME production increased linearly along the time. Oleic acid was also followed, which is the FFA with major presence in the substrate. In this case, it can be noted the decreasing of this component during the reaction, indicating that the esterification rate was higher than the hydrolysis one.

\subsection{Stability-testing reaction cycles}

It has been tested in past studies that lipases have a noticeable decrease in their activity when put in contact with methanol in the reaction media over long periods of time (Noureddini 2005). Thus, a serial of biodiesel synthesis reaction cycles were performed in order to evaluate its stability.

As presented in Fig. 5, a total of 7 cycles were carried out which corresponded to 26 hours of reaction. Considering the first one's yield as the maximum that could be obtained, it was compared to the successive ones in order to determine the evolution of the biocatalyst deactivation along the reutilisations. Nearly a $64 \%$ of the initial yield was maintained after 26 hours of reaction. Despite the long exposure to methanol in the reaction media, these results showed that activity of biocatalyst was well preserved when using alperujo oil as a substrate, although it is not possible to distinguish if the lost activity is due to an inactivation or a possible leaching effect.

\section{Conclusions}

During the immobilisation procedure higher loads of lipase activity were obtained at $25^{\circ} \mathrm{C}$ comparing with a temperature of $4^{\circ} \mathrm{C}$ without loss of activity. The UA immobilised per $\mathrm{mg}$ of support was twofold higher in commercial support probably due to the highest superficial area exposed to biocatalyst. However, when both biocatalysts were tested in a biodiesel 
reaction the initial rate expressed as $\mu$ mol FAME ml-1 ml-1 UA-1 were of the same order of magnitude demonstrating $\mathrm{RH} 26$ has a similar performance of commercial ones. Thus, $\mathrm{RH} 26$ could be considered as a potential carrier alternative to RelOD. However, the main drawback of this cheap support is the not easy recovery for a possible reutilization in successive biotransformations due to its intrinsic characteristics comparing with commercial ones. This point should be improved for a future application as support of lipase in the enzymatic production of biodiesel. In the case of rROL immobilised on commercial support, high yield values were achieved as well as high stability values were obtained after 26 hours of reaction, demonstrating the efficiency of this carrier.

\section{Acknowledgements}

This work was supported by the project CTQ2016-74959-R of the Spanish Ministry of Economy and Competitiveness. The group is member of 2014-SGR-452 and the Reference Network in Biotechnology (XRB) (Generalitat de Catalunya).

Declaration of interest: The authors report no conflicts of interest. The authors alone are responsible for the content and writing of the paper.

\section{References}

Almeida TA, Rodrigues IA, Estrela TS, Nunes CNF, Machado LL, Leao KV, Barros ICL, Amorim FAC, Braga VS. 2016. Synthesis of ethyl biodiesel from soybean oil, frying oil and chicken fat, using catalysts based on vanadium pentoxide. Energy 97: 528-533.

Andreola F, Martín MI, Ferrari AM, Lancellotti I, Bondioli F, Rincon JMA, Romero M, Barbieri L. 2013. Ceram Int 39: 5427-5435.

Arnau, C., Ramon, R., Casas, C., \& Valero, F. 2010. Optimization of the heterologous production of a Rhizopus oryzae lipase in Pichia pastoris system using mixed substrates on controlled fedbatch bioprocess. Enzyme Microb. Technol. 46:494-500.

Bonet-Ragel K, Canet A, Benaiges MD, Valero F. 2015. Synthesis of biodiesel from high FFA alperujo oil catalysed by immobilised lipase. Fuel 161: 12-17.

Calero J, Verdugo C, Luna D, Sancho ED, Luna C, Posadillo A, Bautista FM, Romero AA. 2014. Selective ethanolysis of sunflower oil with Lipozyme RM IM, an immobilized Rhizomucor 
miehei lipase, to obtain a biodiesel-like biofuel, which avoids glycerol production through the monoglyceride formation. N Biotechnol 31: 596-601.

Canet A, Benaiges MD, Valero F. 2014. Biodiesel synthesis in a solvent free system by recombinant Rhizopus oryzae lipase. Study of the catalytic reaction progress. J Am Oil Chem Soc 91:1499-1506.

Canet A, Bonet-Ragel K, Benaiges MD, Valero F. 2016. Lipase-catalyzed transesterification: Viewpoint of the mechanism and influence of free fatty acids. Biomass and Bioenergy 85: 9499.

Canet A, Bonet-Ragel K, Benaiges MD, Valero F. 2017. Biodiesel synthesis in a solvent-free system by recombinant Rhizopus oryzae: Comparative study between a stirred tank and a packed-bed batch reactor. Biocat Biotransfor. 35(1):35-40

Della VP, Kühn I, Hotza D. 2002. Rice husk ash as an alternate source for active silica production. Materials Letters. 57(4):818-821

Duarte SH. Hernandez GLP, Canet, A, Benaiges MD, Maugeria F, Valero, F. 2015. Enzymatic biodiesel synthesis from yeast oil using immobilized recombinant Rhizopus oryzae lipase. Bioresource Technol 183: 175-180.

Fan X, Niehus X, Sandoval G. 2012. Lipases and Phospholipases: Methods and Applications. Methods in Molecular Biology. Springer-Humana Press. NY USA. p. 471-483.

Gog A, Roman M, Tosa M, Paizs C, Irimie FD. 2012. Biodiesel production using enzymatic transesterification - current status and perspectives. Renew Energy 39:10-16.

Hama S, Tamalampudi S, Yoshida A, Tamadani N, Kuratani N, Noda H, Fukuda H, Kondo A. 2011. Process engineering and optimization of glycerol separation in a packed-bed reactor for enzymatic biodiesel production Bioresource Technol 102: 10419-10424.

Ismail SAA, Ali RFM. 2015. Physico-chemical properties of biodiesel manufactured from waste frying oil using domestic adsorbents. Sci Tecnol Adv Mater 16: 1-9.

Juan JC, Kartika DA, Wub TY, Hin, TY, 2011. Biodiesel production from jatropha oil by catalytic and non-catalytic approaches: An overview. Bioresource Technol 102: 452-460.

Kaieda, M., Samukawa, T., Matsumoto, T., Ban, K., Kondo, A., Shimada, Y., Fukuda, H., 1999. Biodiesel fuel production from plant oil catalyzed by Rhizopus oryzae lipase in a watercontaining system without an organic solvent. J Bioscience and Bioengineering 88(6):627-631

Kuo, T, Shaw J, Lee G. 2015. Conversion of crude Jatropha curcas seed oil into biodiesel using liquid recombinant Candida rugosa lipase isozymes. Bioresource Technol 192: 54-59.

Lotti, M, Pleiss, J, Valero, F, Ferrer, P, 2015. Effects of methanol on lipases: Molecular, kinetic and process issues in the production of biodiesel. Biotechnol J 10: 1-9.

Martin MA, Yates M, Plou F, Lozano R, Saex E, Martínez AM, Vega L, Medina L, Zurdo V, Ramos M, Valero F, Benaiges MD. 2013. Patent P201230114 Spain. 
Masel, RI. 1996. Principles of Adsorption and Reaction on Solid Surfaces. John Wiley \& Sons Vol. 3

Mateo, C., Palomo, J. M., Fernandez-lorente, G., Guisan, J. M., \& Fernandez-lafuente, R. 2007. Improvement of enzyme activity, stability and selectivity via immobilisation techniques. Enzyme Microb. Technol. 40:1451-1463

Noureddini, H., Gao, X., \& Philkana, R. S. 2005. Immobilized Pseudomonas cepacia lipase for biodiesel fuel production from soybean oil. Bioresour. Technol. 96:769-777.

Pode R. 2016. Potential applications of rice husk ash water from rice husk biomass power plant. Renew Sust Energ Rev 53: 1468-1485.

Resina D, Serrano A, Valero F, Ferrer P. 2004. Expression of a Rhizopus oryzae lipase in Pichia pastoris under control of the nitrogen source-regulated formaldehyde dehydrogenase promoter. J Biotechnol. 109:103-13

Rodrigues J, Canet A, Rivera I, Osorio NM, Sandoval G, Valero F, Ferreira-Dias S. 2016. Biodiesel production from crude jatropha oil catalyzed by non-commercial immobilized heterologous Rhizopus oryzae and Carica papaya lipase. Bioresource Technol 213: 88-95.

Saengprachum N, Pengprecha S. 2016. Preparation and characterization of aluminium oxide coated extracted silica from rice husk ash for monoglyceride removal in crude biodiesel production. J Taiwan Inst Chem E 58: 441-450.

Srivastava VC, Mall ID. 2005. Characterization of mesoporous rice husk ash (RHA) and adsorption kinetics of metal ions from aqueous solution onto RHA. J Hazardous Mat. 134(13):257-267

Turmanova S, Genieva S, Vlaev L. 2012. Obtaining some polymer composites filled with rice husks ash-a review. Int J Chem 4(4): 62-89.

Ulker C, Gokalp N, Guvenilir Y. 2016a. Immobilisation of Candida antarctica lipase B (CALB) on surface-modified rice husk ashes (RHA) via physical adsorption and cross-linking methods. Biocatal Biotransfor 34(4): 172-180.

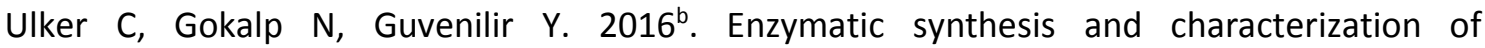
polycaprolactone by using immobilized lipase onto a surface-modified renewable carrier. Pol J Chem Tech 18(3): 134-140.

Vinh PP. 2012. Utilization of rice husk ash in GeoTechnology (Master of Science Thesis) Netehrlands. Faculty of Civil Engineering and Geosciences. Delft University of Technology.

You Q, Yin X, Zhao Y, Zhang Y. 2013. Biodiesel production from jatropha oil catalyzed by immobilized Burkholderia cepacia lipase on modified attapulgite. Bioresource Technol 148: 202-207. 
Table 1 Effect of initial lipolytic activity (expressed in $\mathrm{UA} / \mathrm{mL}$ ) at two different temperatures $\left(4^{\circ} \mathrm{C}\right.$ and $\left.25^{\circ} \mathrm{C}\right)$.

\begin{tabular}{lll} 
Time $(\mathrm{min})$ & Lipolytic Activity $\left(4^{\circ} \mathrm{C}\right)$ & Lipolytic Activity $\left(25^{\circ} \mathrm{C}\right)$ \\
\hline 0 & $106.74 \pm 2.56$ & $106.97 \pm 0.11$ \\
60 & $104.01 \pm 3.45$ & $102.30 \pm 2.70$ \\
120 & $100.52 \pm 3.83$ & $108.92 \pm 1.68$ \\
360 & $98.40 \pm 2.76$ & $110.24 \pm 2.22$ \\
\hline
\end{tabular}


Table 2 Overview of most significant results and previous works references.

\begin{tabular}{lllll}
\hline Support & $\begin{array}{c}\text { Specific activity } \\
(\mathrm{UA} / \mathrm{mg} \\
\text { support })\end{array}$ & $\begin{array}{c}\text { Initial rate } \\
(\mu \mathrm{mol}\end{array}$ & $\begin{array}{c}\text { Total } \\
\mathrm{UA} / \text { reaction }\end{array}$ & $\begin{array}{c}\text { Normalised initial rate } \\
(\mu \mathrm{mol} \text { FAME } / \mathrm{mL} \cdot \mathrm{min} \cdot \mathrm{UA})\end{array}$ \\
\hline RH26 & 27 & 4.39 & 3500 & 1.25 \\
RH26 & 48.09 & 9.97 & 6250 & 1.59 \\
RelOD & 46.21 & 16.48 & 6931 & 2.37 \\
RelOD & 90.29 & 18.88 & 13543 & 1.39 \\
\hline
\end{tabular}


Figure 1. Immobilisation yield versus initial lipolytic activity loaded at $4{ }^{\circ} \mathrm{C}$ (filled circles) and $25^{\circ} \mathrm{C}$ (empty circles) using RelOD support. Specific activity of biocatalyst at the end of the immobilisation at $4{ }^{\circ} \mathrm{C}$ (filled triangles) and $25^{\circ} \mathrm{C}$ (empty triangles).

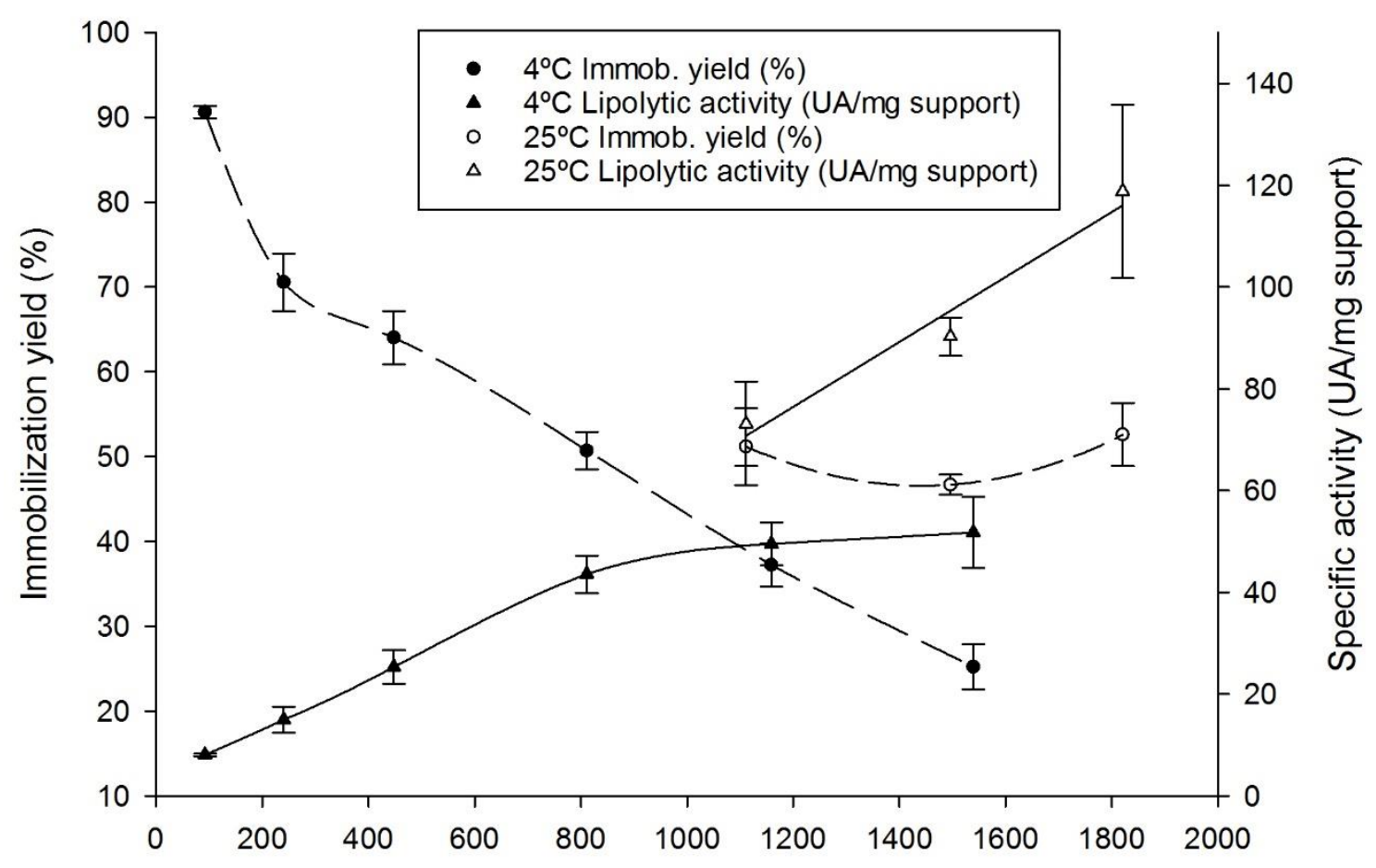

Initial lipolytic activity (UA/mL solution) 
Figure 2. Immobilisation yield using RH26 support versus initial lipolytic activity loaded at $25^{\circ} \mathrm{C}$ (filled circles) specific activity of biocatalyst (empty circles).

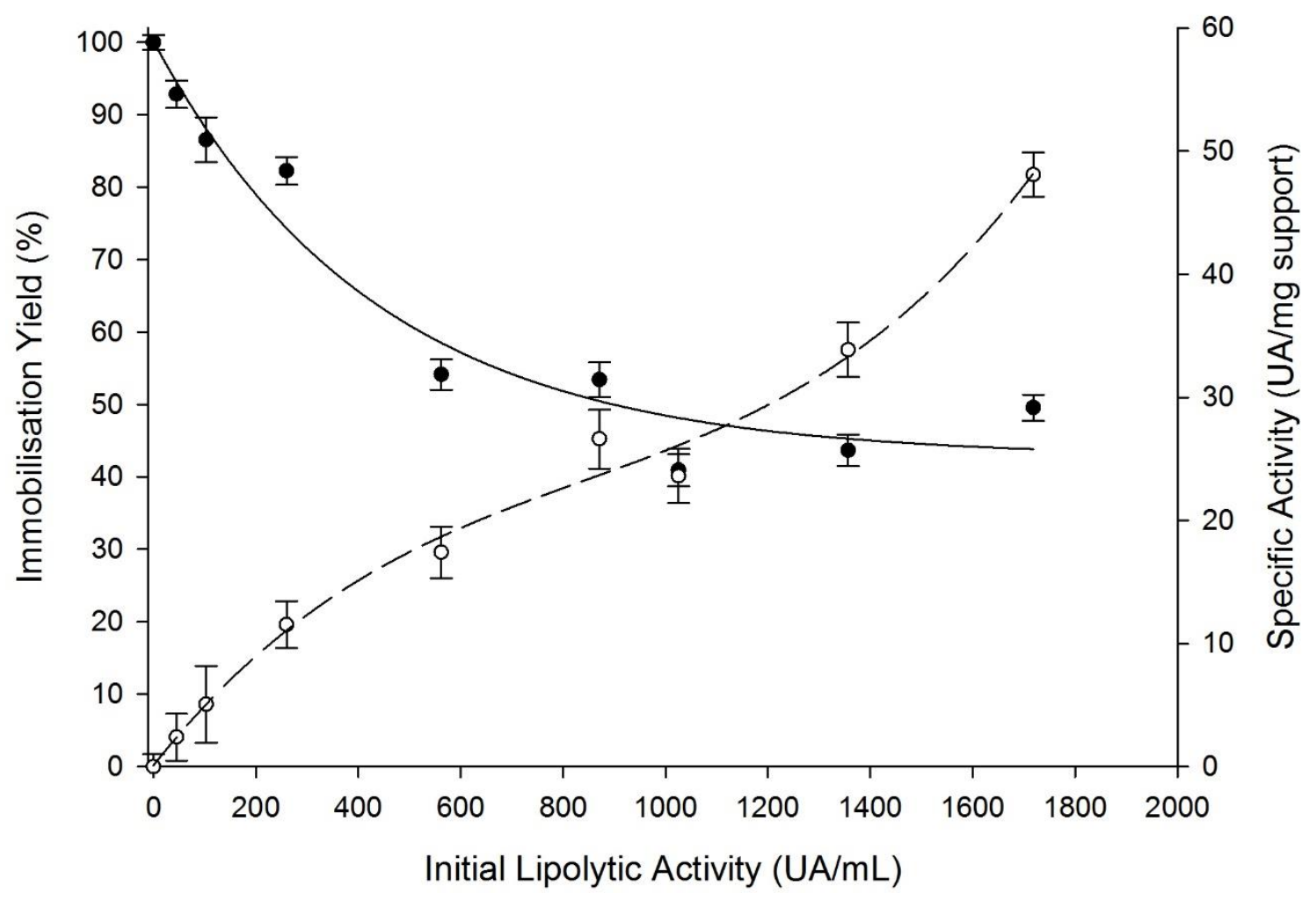


Figure 3. Biodiesel transesterification initial rates using both biocatalysts ( $\mathrm{RH} 26$, on filled circles and RelOD, on empty triangles) depending on its specific activity (UA/mg support).

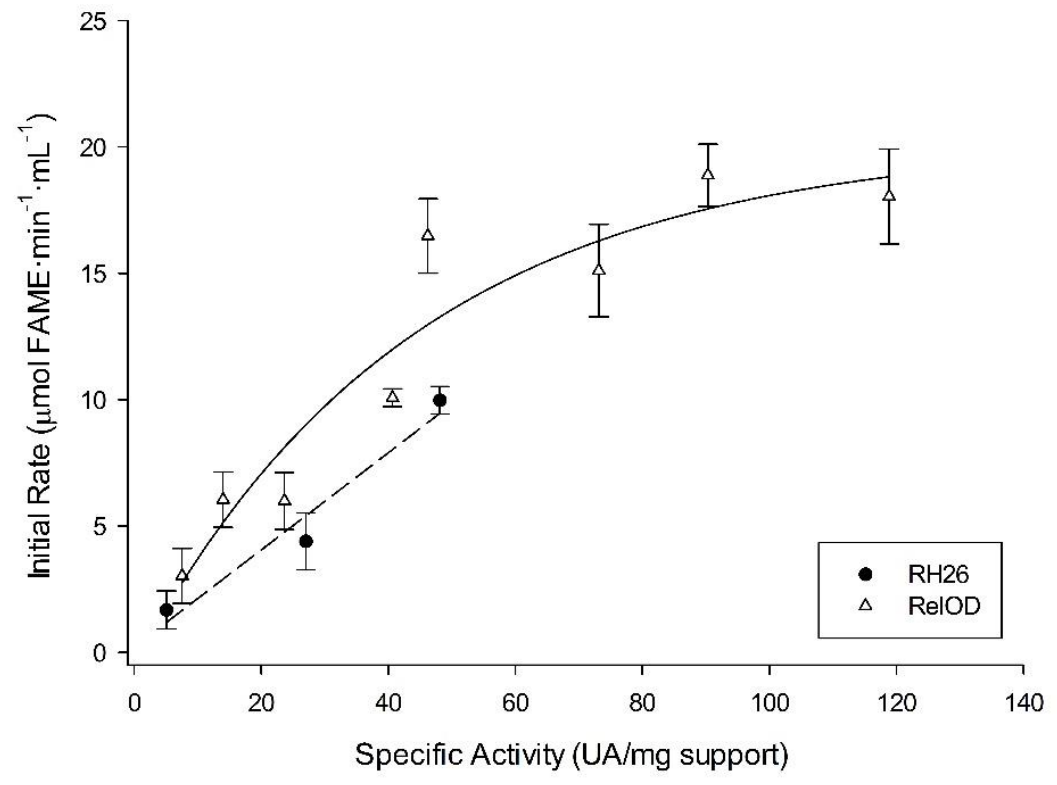


Figure 4. FAME yield and total oleic acid amount during a complete transesterification using RelOD as a support and alperujo oil as a substrate. Pulses of methanol were added before the very fourth samples.

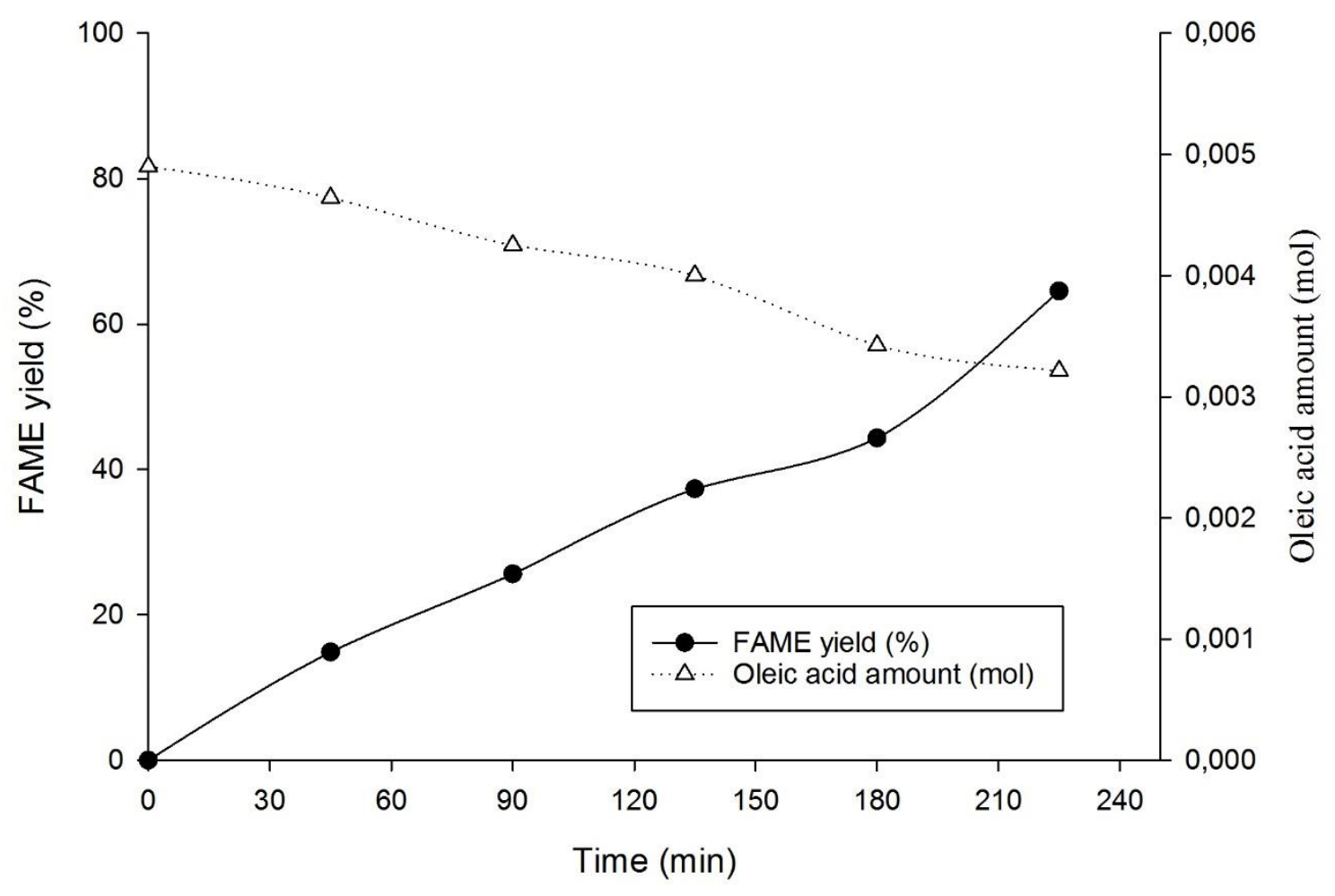


Figure 5. Relative activity for each reaction cycle taking the first reaction yield as the $100 \%$ of biocatalyst activity.

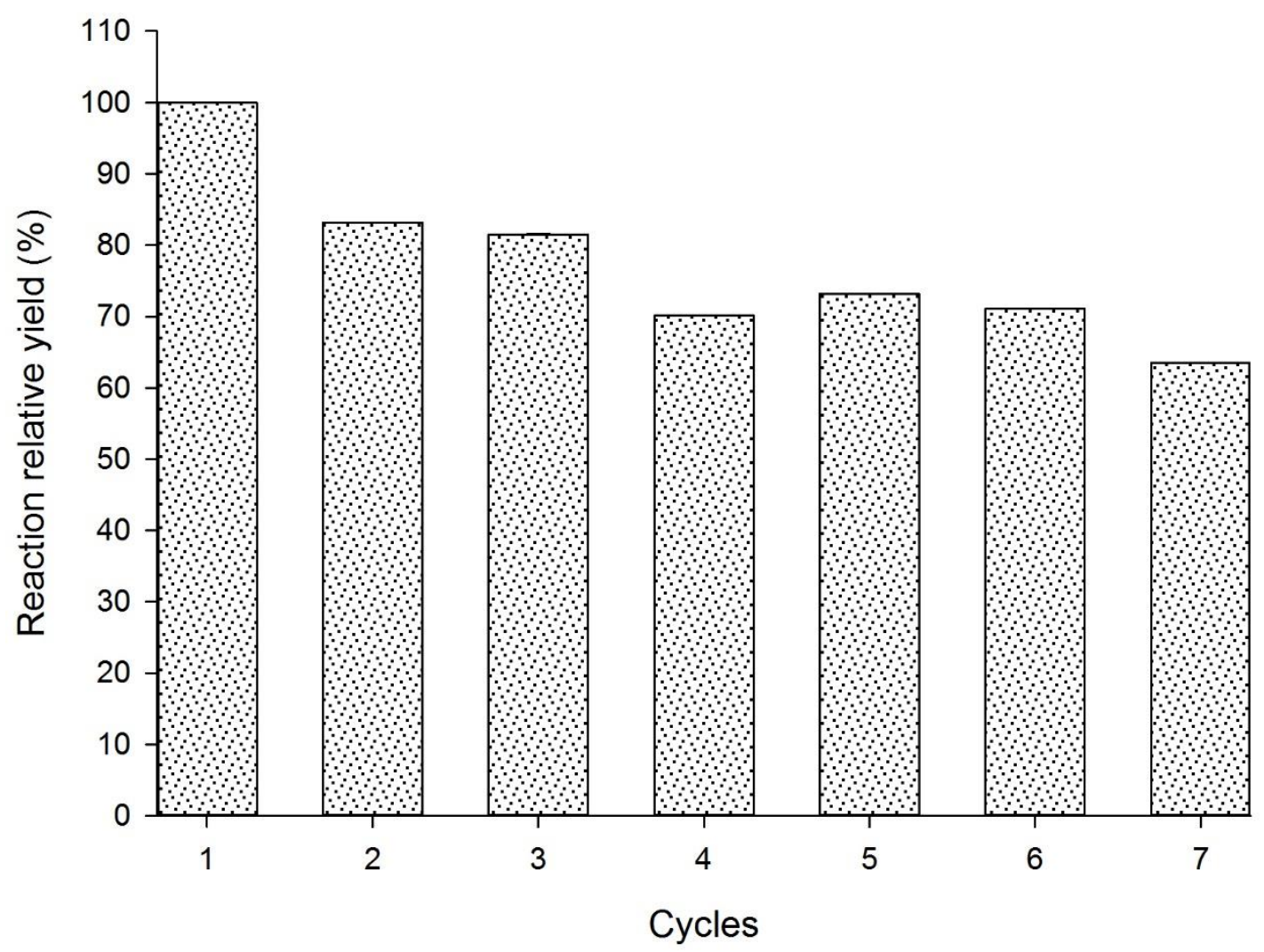


